\title{
Impact of Notch Geometry on the Pressure Bearing Capacity of AISI 316L Austenitic Stainless Steel under Fatigue Loading
}

\author{
J. Jagadesh Kumar ${ }^{1, *}$, G. Diwakar ${ }^{1}$, V. V. Satyanarayana ${ }^{2}$ \\ ${ }^{1}$ Department of Mechanical Engineering, Koneru Lakshmaiah Education Foundation (Deemed to be University), India \\ ${ }^{2}$ Department of Mechanical Engineering, Vidya Jyothi Institute of Technology, India
}

Received August 28, 2019; Revised October 12, 2019; Accepted October 22, 2019

Copyright $\bigcirc 2019$ by authors, all rights reserved. Authors agree that this article remains permanently open access under the terms of the Creative Commons Attribution License 4.0 International License

\begin{abstract}
In the current research, pressure bearing capacity of AISI 316L austenitic stainless steel is evaluated under fatigue loading through finite element method (ANSYS 18.1) for a specimen with no notch on its surface. Thereafter, the pressure bearing capacity of the same specimen is evaluated with rectangular and V-notches at the center. The notch geometry is changed in terms of its width, depth and the notch central angle (perimeter length) for each of the rectangular and V-notched cases. Fifteen types of rectangular notch and V-notch geometries are undertaken for the research as required by Box-Behnken model of Response Surface Methodology (RSM) analysis. The primary objective of the research is to evaluate the impact of notch geometry on the pressure bearing capacity under fatigue loading conditions. It is observed that fatigue life degraded more with V-notched specimens when compared to rectangular notched ones. Regression equations are developed and surface plots are generated for both rectangular and $\mathrm{V}$-notch cases for the pressure bearing capacity which is dependent on width, depth and notch central angle.
\end{abstract}

Keywords Fatigue Loading, Box-Behnken Model, Response Surface Methodology (RSM), Analysis of Variance (ANOVA)

\section{Introduction}

When a material is subjected to repeated cycles of stress or strain, failure occurs by leading to fracture at some weak points and this type of a failure is termed as Fatigue. Fatigue deformation is caused by the synchronous action of cyclic stress, tensile stress, and plastic strain. The plastic strain occurring from cyclic stress initiates the crack, the tensile stress promotes the crack growth (propagation). Cautious computation of strain depict that microscopic plastic strains could exist at low levels of stress where the strain might otherwise appear to be totally elastic. Though compressive stresses do not cause fatigue failure, compressive loads may induce local tensile stresses [1]. It is necessary to take some measures to increase fatigue life of components either by changing the geometry of the components or reducing the resistance opposed by the material. Geometry change is often not a solution, especially due to design requirements. Thereby fatigue life of component is increased by decreasing the strains in the material. Various ways such as heat treatment, coating, etc can increase fatigue life of material. M.Makkonen et. al. investigated the fatigue behaviour of grooved tempered steel specimens and concluded that one single method cannot predict the fatigue limit of blunt notches and sharp notches [2]. G.H.Majzoobi et. al. investigated the impact of notch geometry on the fatigue life of high strength and low strength steels. The results showed that the notch geometry has profound effect on fatigue life of a shaft. Three types of notch geometries, V-shape, U-shape and rectangular-shape notches of various sizes are considered for their investigation and maximum and minimum fatigue life reduction occurred for the $\mathrm{V}$-shape and U-shape notches. It was further concluded that, the smaller the tip radius and open angle of notch, lower the fatigue life of shaft with a circumferential notch. Higher the depth of the notch, lower is the fatigue life due to the short propagation of the crack $[3,4]$. M.T.Yu et. al. investigated the fatigue behavior of SAE 1045 steel and concluded that the fatigue notch factor increases with notch diameter for sharp notches, but it decreases with notch diameter for blunt notches [5]. G.Pluvinage depicted that fatigue and fracture are not governed by the local maximum stress (or strain or strain energy density). Hot spot approach always gives an 
overestimation of the fracture or fatigue stress. The stress distribution exhibits a strong gradient which plays an important role [6]. Xuteng $\mathrm{Hu}$ et. al. studied the Effect of notch geometry on the fatigue strength of TC4 titanium alloy and concluded that notch with small radius can lead to high stress concentration and seriously reduce the HCF strength. Further it was concluded that the notch angle and notch depth can affect the HCF strength to a certain extent [7]. Yoshiaki Akiniwa et. al. studied the effect of notch on fatigue strength reduction of bearing steel in very high cycle regime and proved that for circumferentially notched specimens, fatigue fracture originated from the surface or very close to the surface. The slip deformation was root cause for crack initiation in high cycle and very high cycle regimes. The fatigue strength of specimens with notch was less than that of smooth specimens. The extent of reduction was observed to be smaller at longer lives [8].

In the current research, pressure bearing capacity of AISI $316 \mathrm{~L}$ austenitic stainless steel is evaluated under fatigue loading through finite element method (ANSYS 18.1) for a specimen with no notch on its surface. Thereafter, the pressure bearing capacity of the same specimen is evaluated with different types of notches on the surface. The notch geometry is changed in terms of its width, depth and the notch central angle (perimeter length). Two variants of notches, viz. rectangular and V-notch are created at the center of the specimen. Fifteen types of notch geometries are undertaken for each of the notch variants as required by Box-Behnken model of Response Surface Methodology (RSM) analysis. The primary objective of the research is to evaluate the impact of notch geometry on the pressure bearing capacity under fatigue loading conditions.

\section{Experimental Methodology}

\subsection{Material}

AISI 316L austenitic stainless steel is primarily used in naval and marine applications owing to its excellent corrosion resistance and high strength to weight ratio. The chemical and mechanical properties of the material are given in Table 1 and Table 2 respectively.

\subsection{Specimen}

Fatigue testing is carried out for the chosen material employing the ASTM E606 standard specimen (Figure 1). At the center of the specimen, a notch is made varying the width, depth and length in terms of notch central angle for conducting the experimentation to evaluate the fatigue life. The cross-sectional view of the notches created on the specimens is illustrated in Figure 2.

Table 1. Chemical Composition (wt\%)

\begin{tabular}{|c|c|c|c|c|c|c|c|c|c|c|}
\hline Element & $\mathbf{C}$ & $\mathbf{M n}$ & $\mathbf{S i}$ & $\mathbf{C r}$ & $\mathbf{N i}$ & $\mathbf{M o}$ & $\mathbf{P}$ & $\mathbf{S}$ & $\mathbf{N}$ & $\mathbf{F e}$ \\
\hline$\%$ & 0.03 & 2 & 0.75 & 17.00 & 12.00 & 2.5 & 0.045 & 0.03 & 0.1 & Balance \\
\hline
\end{tabular}

Table 2. Mechanical Properties

\begin{tabular}{|c|c|c|c|c|}
\hline Hardness (BHN) & UTS (MPa) & Yield Strength (MPa) & Poisson's Ratio & Elastic Modulus (GPa) \\
\hline 142 & 485 & 170 & 0.25 & 193 \\
\hline
\end{tabular}

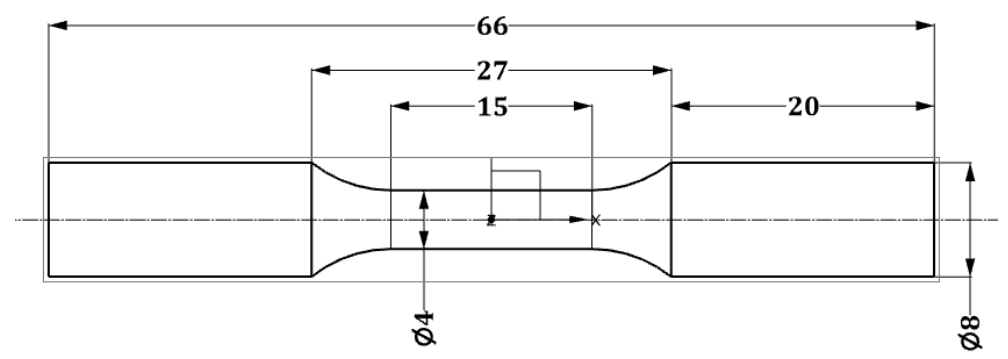

Figure 1. Standard Fatigue specimen

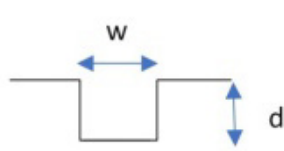

Rectangular Notch

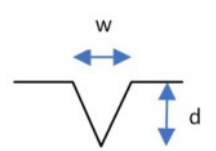

V-notch

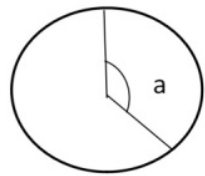

Notch central angle

Figure 2. Notch geometry - Cross sectional view 


\subsection{Solid Model}

The three-dimensional model of the specimen is prepared in CREO 3.0 and exported to Initial Graphics Exchange Specification (IGES) format. The 3-D solid model of the specimen is shown in the Figure 3.

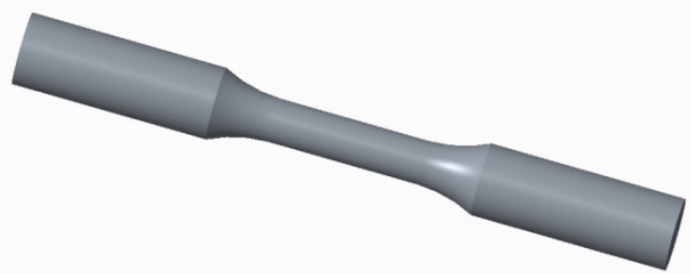

Figure 3. 3-D solid model of the specimen

\subsection{Finite Element Fatigue Analysis}

The finite element fatigue analysis is carried out using ANSYS 18.1 workbench. It is employed to evaluate the applied pressure on the job in order to get the estimated fatigue life in cycles.

\subsubsection{Finite Element Model}

The specimen's 3-D model in IGES format is imported into ANSYS 18.1 and then the finite element model of the specimen is prepared by using the ANSYS mesh tool with a refinement level of 3 . The finite element (FE) model is shown in Figure 4.

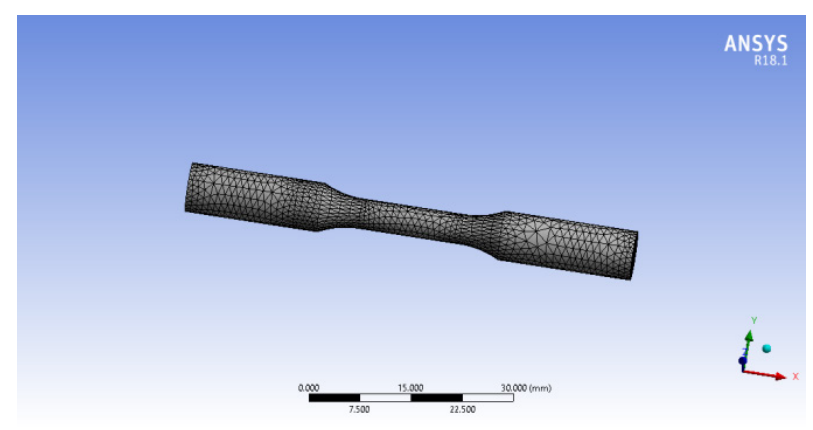

Figure 4. Finite Element model of the specimen

\subsubsection{Boundary Conditions}

The left end of the specimen is fixed by applying a support at that end. A pressure of required magnitude is applied on the right end of the specimen. The maximum Von-Mises (Equivalent) stress induced is maintained at approximately $400 \mathrm{MPa}$ so that the fatigue life is always around 25800 cycles. This is achieved by the iterative approach of altering pressure so that the maximum Von-Mises stress is around $400 \mathrm{MPa}$. The boundary conditions of a typical specimen without notch are shown in Figure 5.

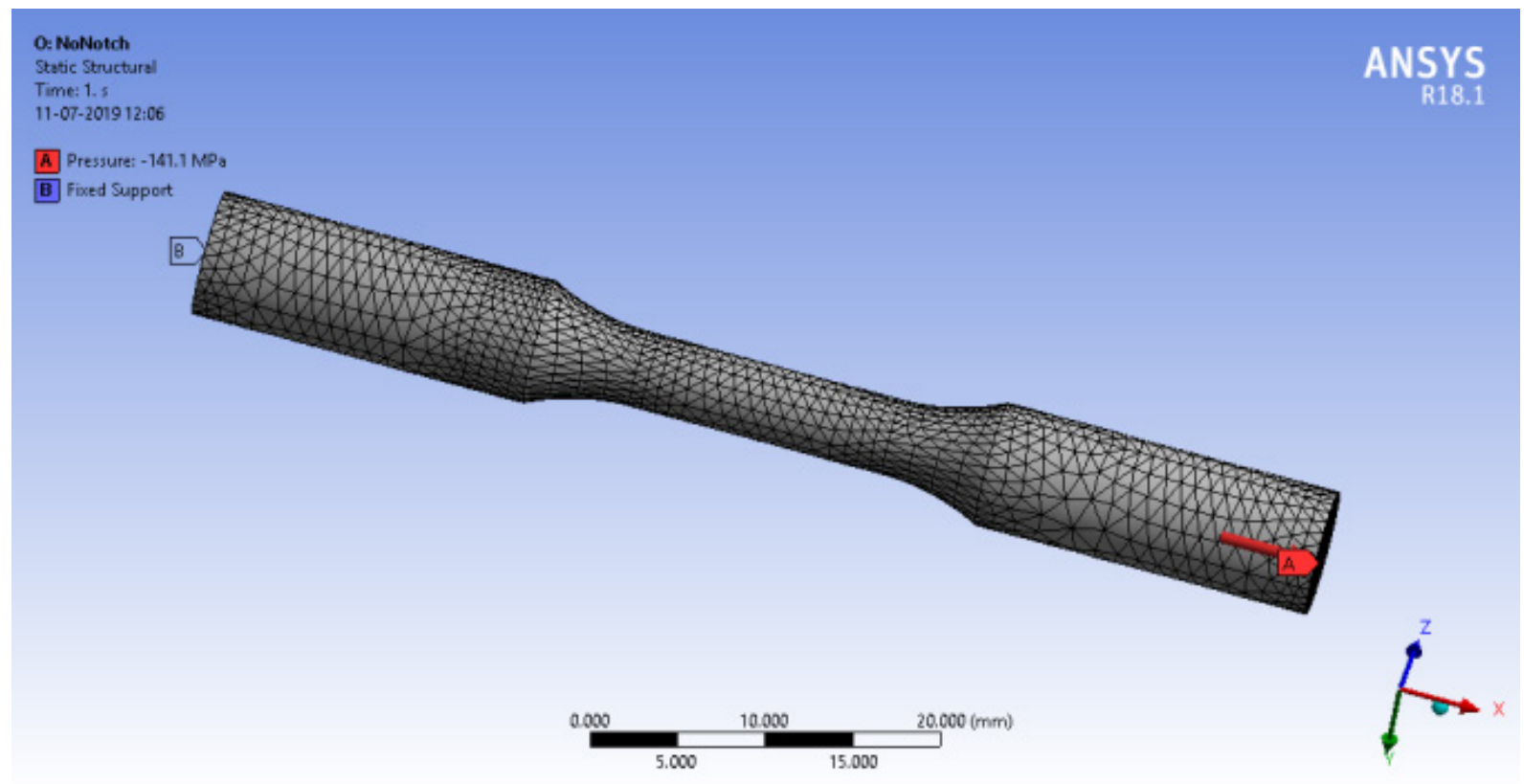

Figure 5. Typical specimen with boundary conditions 


\subsubsection{ANSYS Fatigue Tool}

The strain life approach available in ANSYS 18.1 Fatigue tool out-of-box is considered for the analysis which is undertaken for the current research due to the presence of notch on the geometry of the specimen. Strain-Life approach takes into account, the local plastic strains induced at localized spots. Smith-Watson-Topper method of the strain life approach is used for the research as it gives conservative fatigue life value when compared to Morrow's approach.

\subsection{Design of Experiments}

Several statistical methods exist for the analysis of any research results, however response surface methodology (RSM) technique is chosen in the current research due to its implicit strengths like ease in measuring the effects of parameters and their interactions $[9,10,11]$. Experimentation has been carried out by considering the three parameters each at the three levels as given in Table 3. The Box-Behnken model of the response surface methodology is employed with the chosen parameters and the experimental runs conducted are illustrated in Table 4. A response polynomial is fitted for pressure to be applied for the estimated fatigue life under different parameter combinations and it is in the form;

$\mathrm{y}=\mathrm{b}_{0}+\mathrm{b}_{1} \mathrm{x}_{1}+\mathrm{b}_{2} \mathrm{x}_{2}+\mathrm{b}_{3} \mathrm{x}_{3}+\mathrm{b}_{4} \mathrm{x}_{1}{ }^{2}+\mathrm{b}_{5} \mathrm{x}_{2}{ }^{2}+\mathrm{b}_{6} \mathrm{x}_{3}{ }^{2}+\mathrm{b}_{7} \mathrm{x}_{1} \mathrm{x}_{2}+\mathrm{b}_{8}$ $x_{2} x_{3}+b_{9} x_{1} x_{3}$.

Table 3. Notch details

\begin{tabular}{|c|c|c|c|c|c|c|}
\hline \multirow{2}{*}{ S.No } & \multirow{2}{*}{$\begin{array}{c}\text { Notch } \\
\text { Parameter }\end{array}$} & \multirow{2}{*}{ Notation } & \multirow{2}{*}{ Units } & \multicolumn{3}{|c|}{ Level } \\
\cline { 5 - 7 } & & & 1 & 2 & 3 \\
\hline 1 & Width & $\mathrm{w}$ & $\mathrm{mm}$ & 0.5 & 0.75 & 1 \\
\hline 2 & Depth & $\mathrm{d}$ & $\mathrm{mm}$ & 0.5 & 0.75 & 1 \\
\hline 3 & $\begin{array}{c}\text { Central } \\
\text { angle }\end{array}$ & $\mathrm{a}$ & degrees & 120 & 240 & 360 \\
\hline
\end{tabular}

Table 4. Experimental runs undertaken

\begin{tabular}{|c|c|c|c|}
\hline Run & Notch Width & Notch Depth & Notch central angle \\
\hline 1 & 0.75 & 0.75 & $240^{\circ}$ \\
\hline 2 & 0.75 & 0.5 & $360^{\circ}$ \\
\hline 3 & 0.75 & 0.5 & $120^{\circ}$ \\
\hline 4 & 1 & 0.75 & $120^{\circ}$ \\
\hline 5 & 0.75 & 0.75 & $240^{\circ}$ \\
\hline 6 & 0.5 & 0.75 & $360^{\circ}$ \\
\hline 7 & 1 & 0.75 & $360^{\circ}$ \\
\hline 8 & 0.5 & 0.75 & $120^{\circ}$ \\
\hline 9 & 1 & 0.5 & $240^{\circ}$ \\
\hline 10 & 0.75 & 1 & $360^{\circ}$ \\
\hline 11 & 0.5 & 0.5 & $240^{\circ}$ \\
\hline 12 & 0.75 & 1 & $120^{\circ}$ \\
\hline 13 & 0.5 & 1 & $240^{\circ}$ \\
\hline 14 & 0.75 & 0.75 & $240^{\circ}$ \\
\hline 15 & 1 & 1 & $240^{\circ}$ \\
\hline
\end{tabular}

The coefficients $b_{0}$ to $b_{9}$ are computed by least square method and analysis of variance (ANOVA) is performed by Yate's algorithm. The analysis is conducted at $95 \%$ confidence level and 5\% level of significance.

\section{Results and Discussion}

The Von-Mises stress and fatigue life results of the specimen with no notch on the surface are shown in Figure 6 and Figure 7 respectively. A pressure of $141.1 \mathrm{MPa}$ was required to be applied on the right face of the specimen so that the maximum Von-Mises stress induced was around $400 \mathrm{MPa}$. The fatigue life obtained for this boundary conditions was 25861 cycles. 


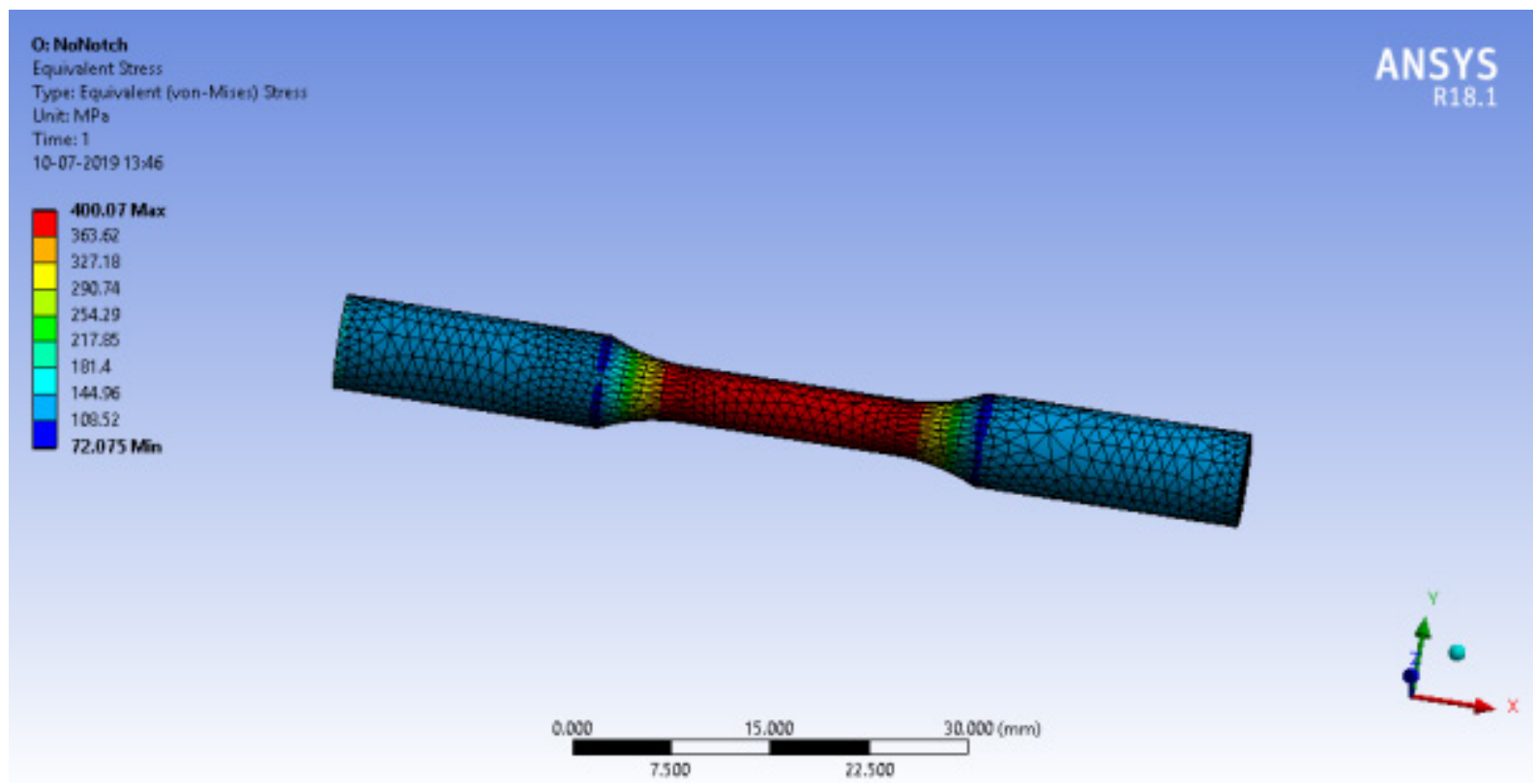

Figure 6. Von-Mises stress of specimen with no notch

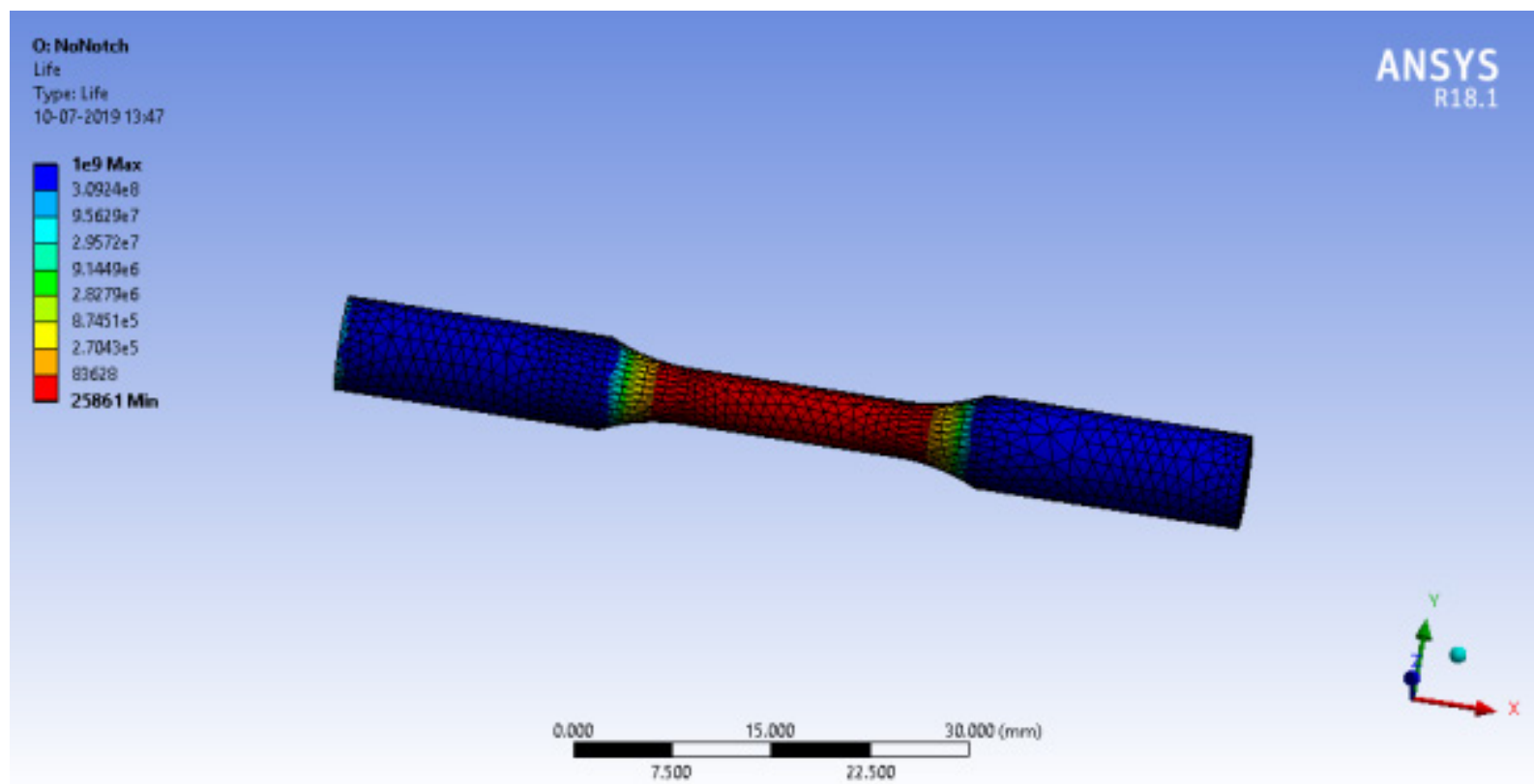

Figure 7. Fatigue Life of the specimen with no notch

The specimens were created with different notches as specified in Table 4 and applied with the boundary conditions at the specific ends by maintaining Von-Mises stress of $400 \mathrm{MPa}$ and fatigue life of 25800 cycles. It is done iteratively for each of the specimens and the applied pressure is evaluated. The applied pressure so obtained for all the specimens are given in Table 5. A typical notched specimen (Run 15) and corresponding results are shown in Figure 8-10 


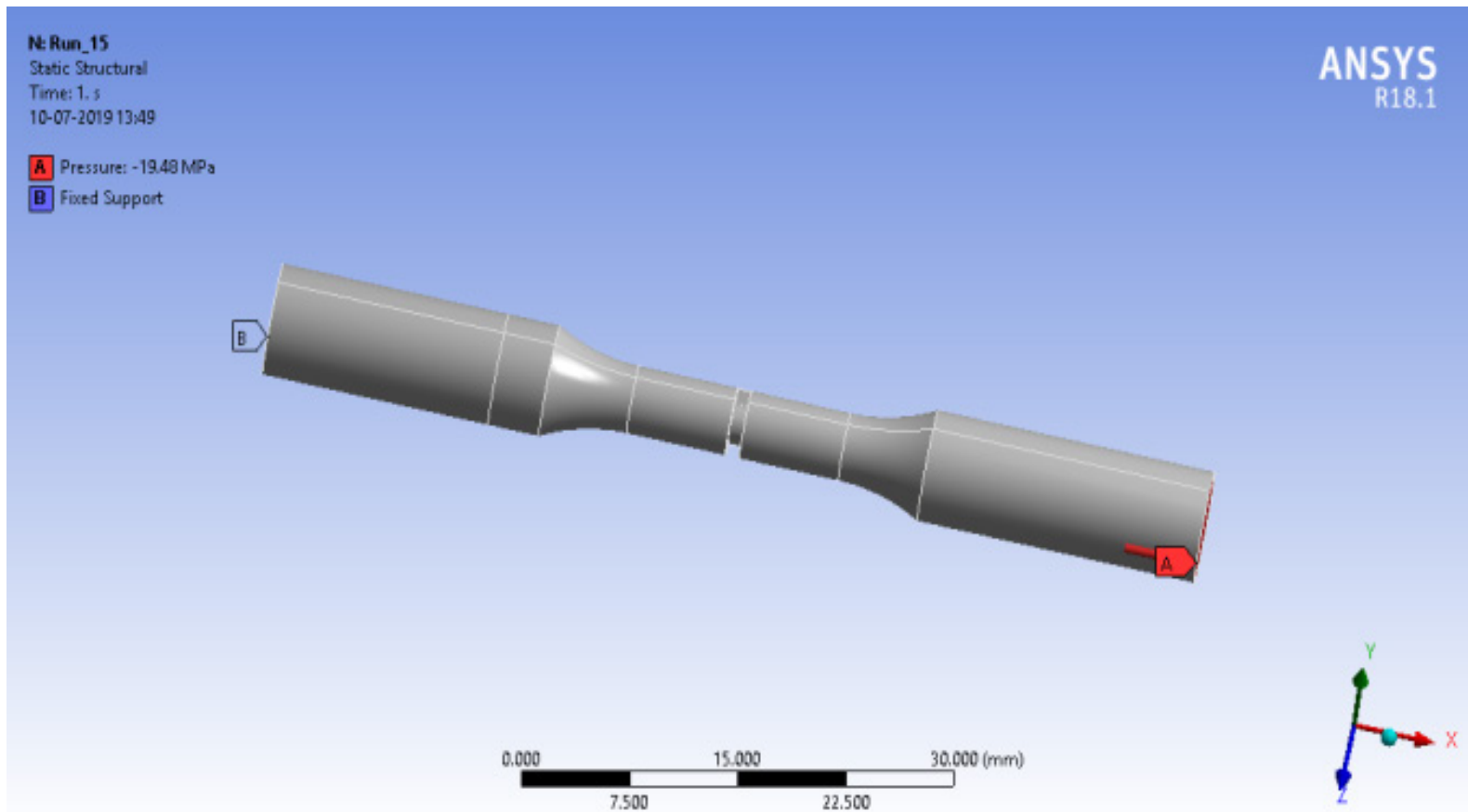

(a) Rectangular notched specimen

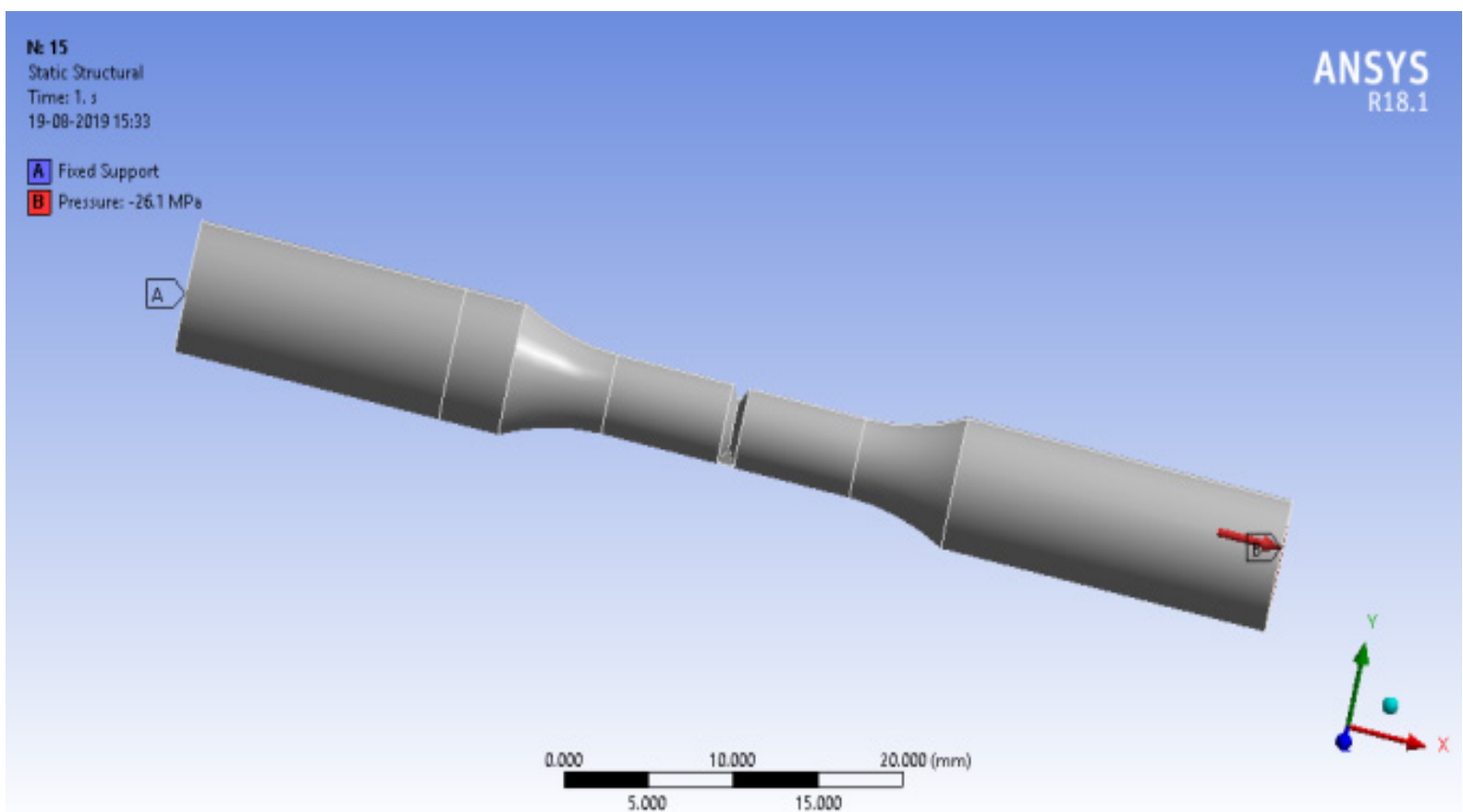

(b) V-notched specimen

Figure 8. 3-D model of the specimen as specified by Run 15 in CREO 3.0 


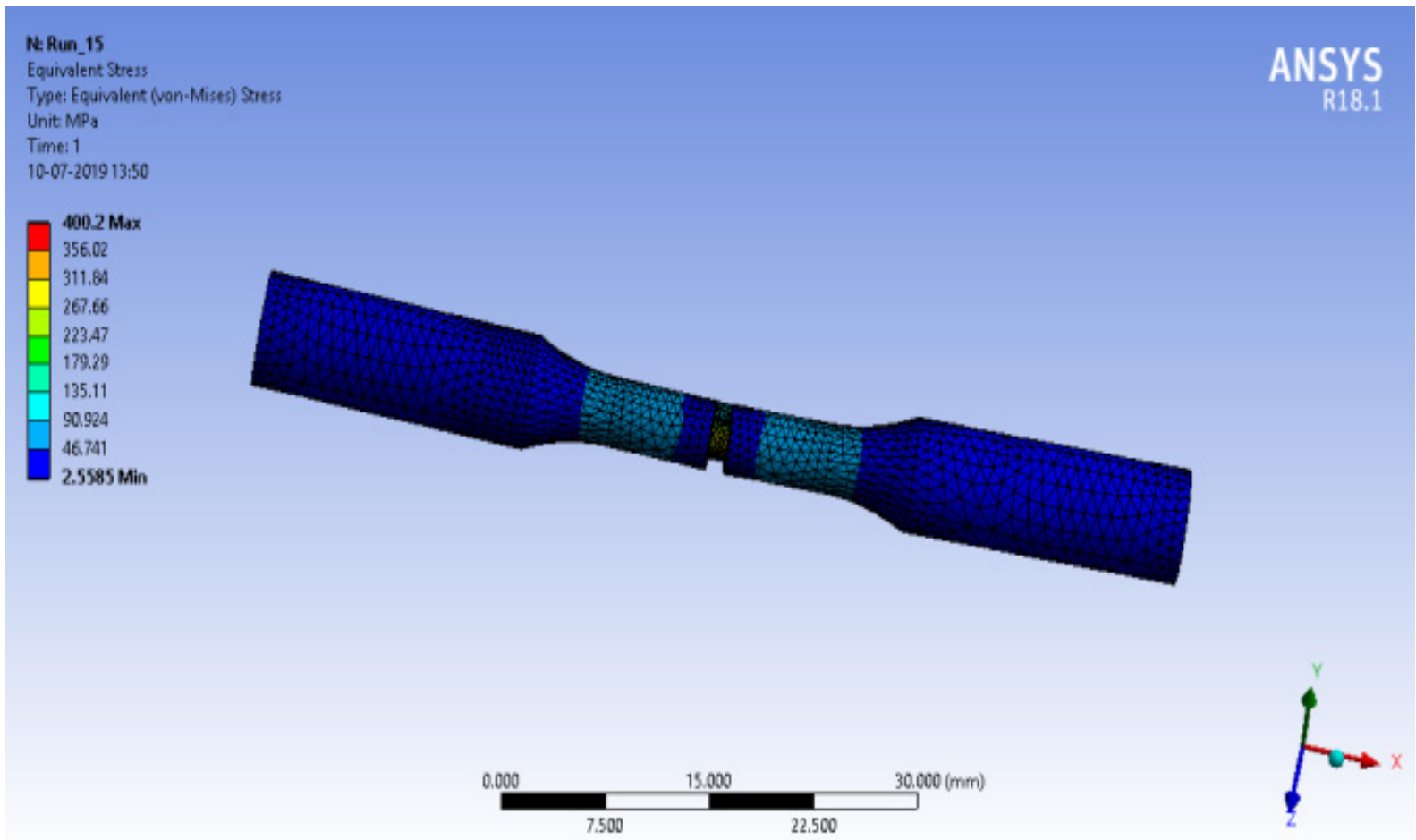

(a) Rectangular notched specimen

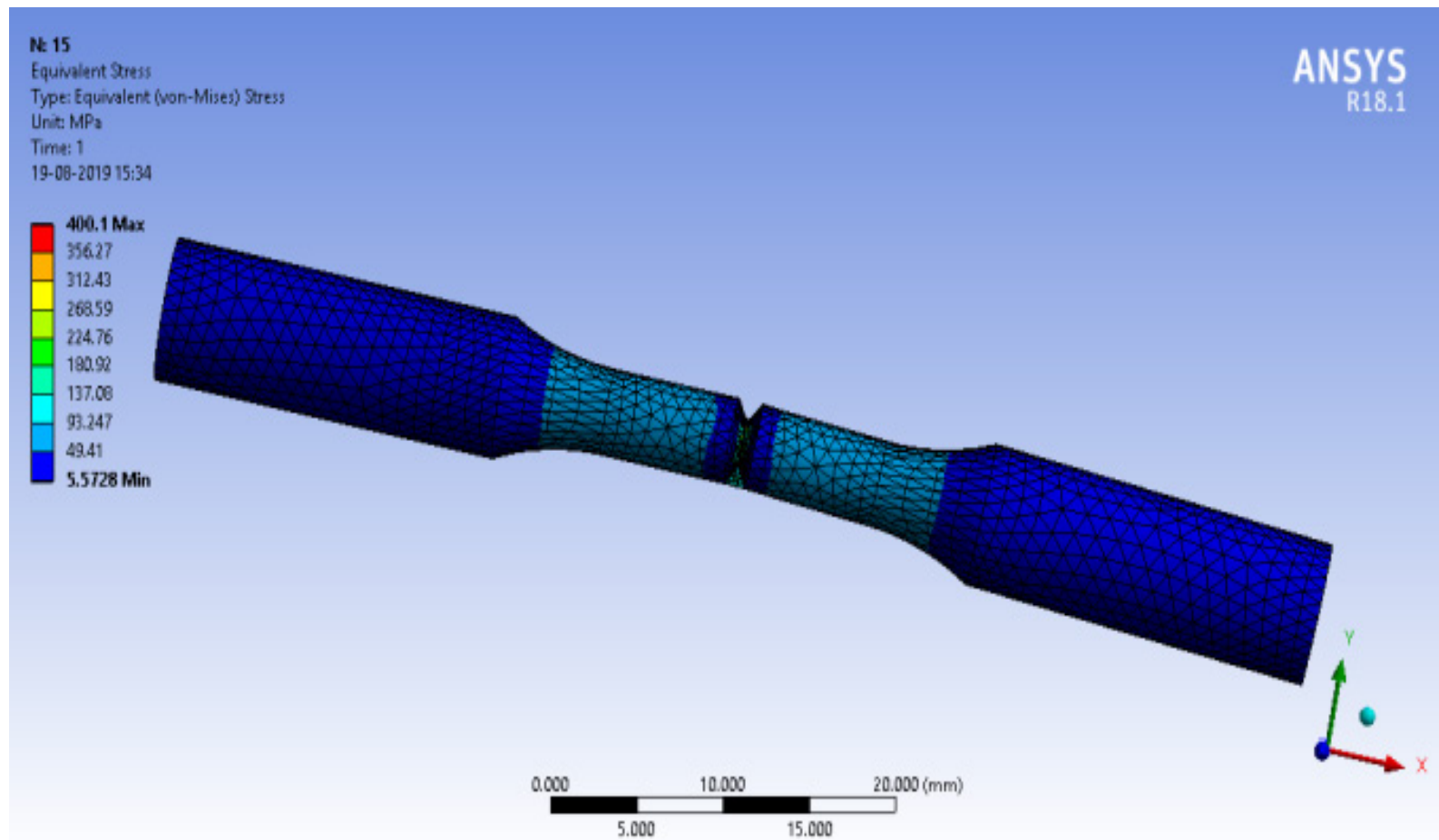

(b) V-notched specimen

Figure 9. Von-Mises stresses for specimen with notch as specified in Run 15 


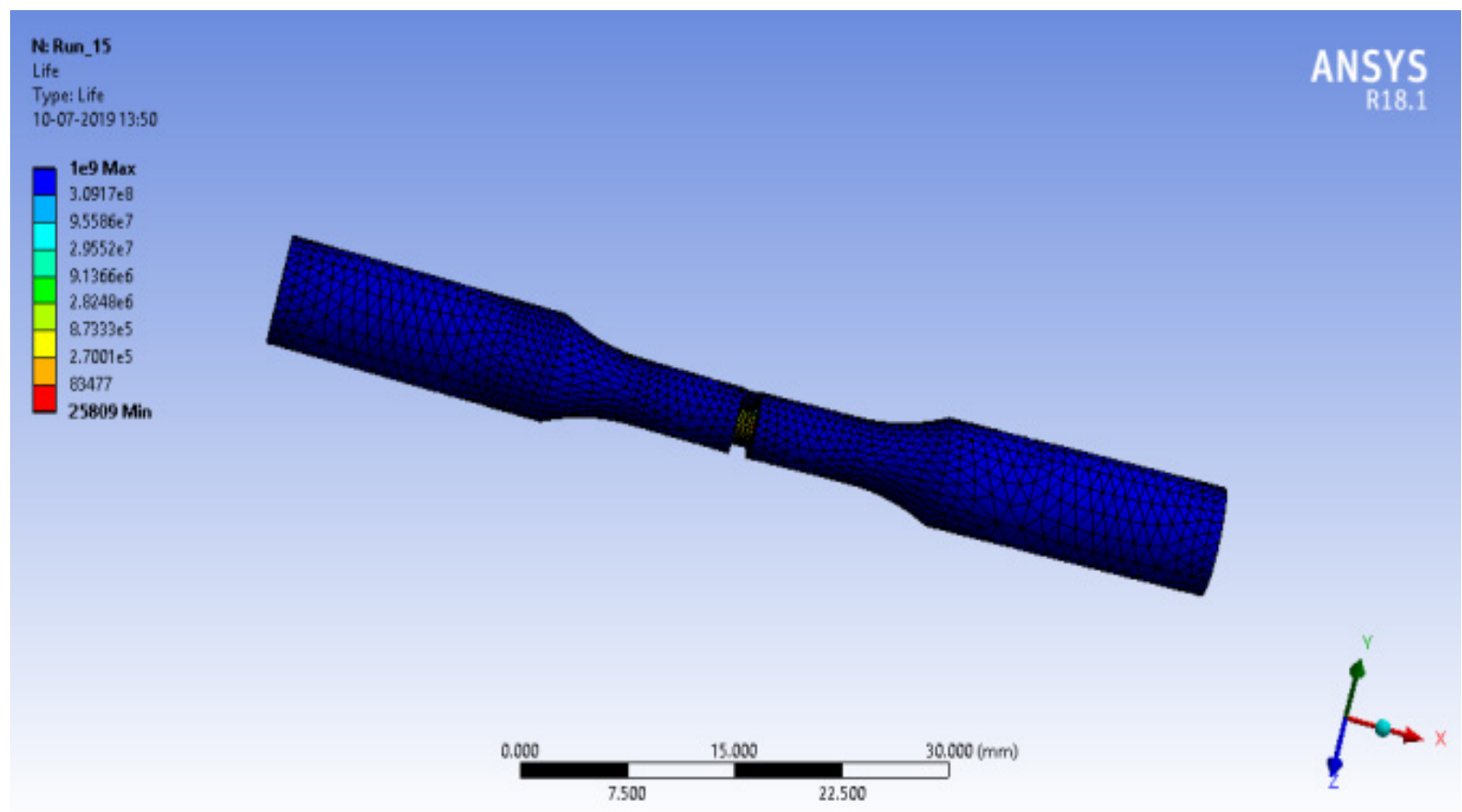

(a) Rectangular notched specimen

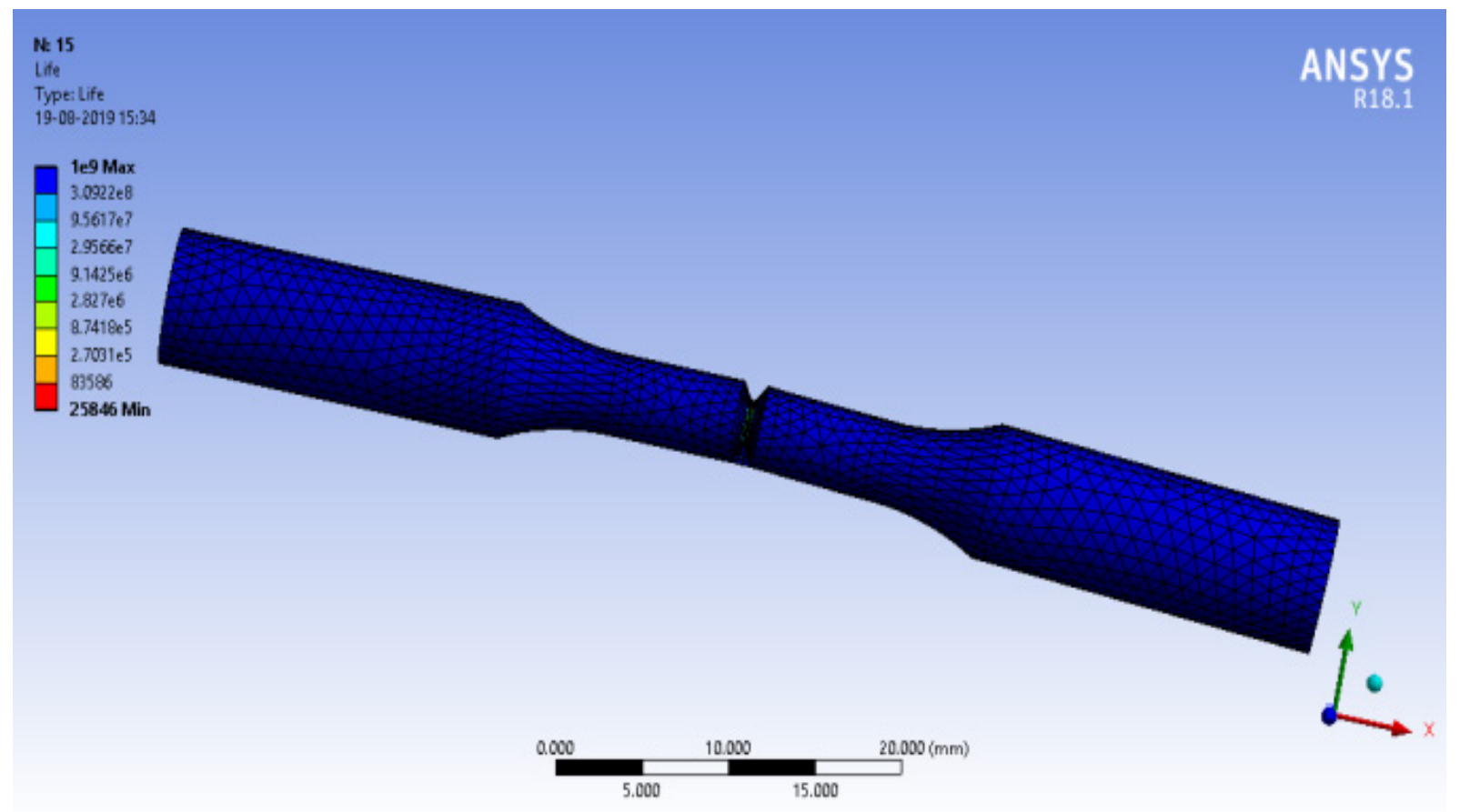

(b) V-notched specimen

Figure 10. Fatigue Life for specimen with notch as specified in Run 15

In the case of rectangular notch, the pressure applied on the specimen is lowest when the depth of the notch is at highest level and the notch central angle is $240^{\circ}$, while the pressure is highest when the notch central angle and depth of notch are at their low levels. It is also found that, when the notch is created throughout its peripheral circumference, the applied pressure was in the range of 28.24 to $46.3 \mathrm{MPa}$, while the pressure is in the range of
34.93 to $52.7 \mathrm{MPa}$ when the notch is restricted to a central angle of $120^{\circ}$. When the notch width is at lowest level, the pressure is in the range of 16.79 to $43.07 \mathrm{MPa}$ and when the width is at highest level, the pressure is in the range of 19.48 to $8.59 \mathrm{MPa}$. The depth of notch caused a pressure range of 43.07 to $52.7 \mathrm{MPa}$ and 16.79 to $34.93 \mathrm{MPa}$ during its lowest and highest levels respectively.

The V-notched specimens, in general show lower 
pressure bearing capacity compared to the rectangular notched specimens. The pressure to be applied is in the range of 26.1 to $37.85 \mathrm{MPa}$ for the V-notched specimens while that of rectangular notched specimens exhibited a higher range of 16.79 to $52.7 \mathrm{MPa}$. It is an indication that fatigue life of rectangular notched specimens is higher than the V-notched specimens. It is also evaluated that the un-notched specimen has a pressure bearing capacity of 141.1 MPa to serve the desired fatigue life. It shows that the fatigue notch factor plays a vital role in the range of 2.5 to 3.5 in the specimens undertaken and higher the notch factor, lower is the fatigue life. The V-notched specimens are more susceptible to form micro-cracks at the root and a steep stresses gradient is formed compared to rectangular notched specimens and hence resulted in lower life or lower pressure bearing range for the given fatigue life. However, a lower pressure bearing capacity is observed in rectangular notched specimens when the width is varying while the other two parameters are at their higher levels compared to V-notched specimens. This can be attributed to the local plastic deformation and notch blunting effect due to yielding at the notch root in case of V-notched specimens, which consequently reduce the notch root stress amplitude compared to rectangular notched specimens.

The results of the fifteen runs (Table 5) are subjected to Response Surface Methodology analysis using the Box-Behnken model. The ANOVA results are computed using Yate's algorithm and presented in Table 6 and Table 7 for rectangular and V-notched specimens respectively;

Table 5. Finite Element Results for rectangular and V-notched specimens

\begin{tabular}{|c|c|c|c|c|c|c|}
\hline \multirow{2}{*}{ Run } & \multirow{2}{*}{$\begin{array}{c}\text { Width } \\
(\mathrm{mm})\end{array}$} & \multirow{2}{*}{$\begin{array}{l}\text { Depth } \\
\text { (mm) }\end{array}$} & \multirow{2}{*}{$\begin{array}{c}\text { Notch central } \\
\text { angle } \\
\text { (degrees) } \\
\end{array}$} & \multirow{2}{*}{$\begin{array}{l}\text { Fatigue Life } \\
\text { (cycles) }\end{array}$} & \multicolumn{2}{|c|}{ Applied Pressure (MPa) } \\
\hline & & & & & Rectangular Notch & V-Notch \\
\hline 1 & 0.75 & 0.75 & $240^{\circ}$ & 25826 & 25.80 & 26.45 \\
\hline 2 & 0.75 & 0.5 & $360^{\circ}$ & 25849 & 46.30 & 40.40 \\
\hline 3 & 0.75 & 0.5 & $120^{\circ}$ & 25855 & 52.70 & 36.15 \\
\hline 4 & 1 & 0.75 & $120^{\circ}$ & 25801 & 46.38 & 34.35 \\
\hline 5 & 0.75 & 0.75 & $240^{\circ}$ & 25826 & 25.80 & 26.45 \\
\hline 6 & 0.5 & 0.75 & $360^{\circ}$ & 25803 & 37.58 & 35.83 \\
\hline 7 & 1 & 0.75 & $360^{\circ}$ & 25835 & 34.59 & 28.53 \\
\hline 8 & 0.5 & 0.75 & $120^{\circ}$ & 25808 & 35.78 & 36.19 \\
\hline 9 & 1 & 0.5 & $240^{\circ}$ & 25844 & 48.59 & 34.25 \\
\hline 10 & 0.75 & 1 & $360^{\circ}$ & 25810 & 28.24 & 29.39 \\
\hline 11 & 0.5 & 0.5 & $240^{\circ}$ & 25818 & 43.07 & 35.50 \\
\hline 12 & 0.75 & 1 & $120^{\circ}$ & 25866 & 34.93 & 23.96 \\
\hline 13 & 0.5 & 1 & $240^{\circ}$ & 25832 & 16.79 & 37.85 \\
\hline 14 & 0.75 & 0.75 & $240^{\circ}$ & 25826 & 25.80 & 26.45 \\
\hline 15 & 1 & 1 & $240^{\circ}$ & 25809 & 19.48 & 26.10 \\
\hline
\end{tabular}

Table 6. ANOVA of results from specimens with rectangular notch

\begin{tabular}{|c|c|c|c|c|}
\hline Source & Sum of Squares & df & Mean Square & F-value \\
\hline $\mathrm{w}$ & 31.28 & 1 & 31.28 & 3.19 \\
\hline $\mathrm{d}$ & 1040.14 & 1 & 1040.14 & 65.98 \\
\hline $\mathrm{a}$ & 66.59 & 1 & 66.59 & 0.78 \\
\hline $\mathrm{wd}$ & 2.00 & 1 & 2.00 & 0.2040 \\
\hline $\mathrm{wa}$ & 46.17 & 1 & 46.17 & 0.0021 \\
\hline $\mathrm{da}$ & 0.0210 & 1 & 0.0210 & 1.68 \\
\hline $\mathrm{w}^{2}$ & 16.46 & 1 & 16.46 & 6.24 \\
\hline $\mathrm{d}^{2}$ & 61.20 & 1 & 61.20 & 42.84 \\
\hline $\mathrm{a}^{2}$ & 420.46 & 1 & 420.46 & \\
\hline SSE & 49.07 & 5 & 9.81 & \\
\hline SST & 1699.16 & 14 & & \\
\hline
\end{tabular}


Table 7. ANOVA of results from specimens with V-notch

\begin{tabular}{|c|c|c|c|c|}
\hline Source & Sum of Squares & df & Mean Square & F-value \\
\hline $\mathrm{w}$ & 61.272 & 1 & 61.272 & 4.31 \\
\hline $\mathrm{d}$ & 105.125 & 1 & 105.125 & 7.39 \\
\hline $\mathrm{a}$ & 1.531 & 1 & 1.531 & 0.11 \\
\hline $\mathrm{wd}$ & 27.563 & 1 & 27.563 & 1.94 \\
\hline $\mathrm{wa}$ & 7.453 & 1 & 7.453 & 0.52 \\
\hline $\mathrm{da}$ & 0.348 & 1 & 0.348 & 0.02 \\
\hline $\mathrm{w}^{2}$ & 62.447 & 1 & 62.447 & 4.39 \\
\hline $\mathrm{d}^{2}$ & 30.254 & 1 & 30.254 & 2.13 \\
\hline $\mathrm{a}^{2}$ & 36.928 & 1 & 36.928 & 2.60 \\
\hline $\mathrm{SSE}$ & 71.150 & 5 & 14.230 & \\
\hline $\mathrm{SST}$ & 387.469 & 14 & & \\
\hline
\end{tabular}

Table 8. Regression Equations

\begin{tabular}{|c|c|c|}
\hline Notch Type & Regression Equation & $\begin{array}{c}\text { Coefficient of } \\
\text { Correlation }\end{array}$ \\
\hline Rectangular & $\mathrm{P}=25.80+1.98 \mathrm{w}-11.40 \mathrm{~d}$ & \\
notch & $2.89 \mathrm{a}+2.11 \mathrm{w}^{2}+4.07 \mathrm{~d}^{2}$ & \\
& $+10.67 \mathrm{a}^{2}-0.71 \mathrm{wd}-3.40 \mathrm{wa}$ & 0.985 \\
& $-0.07 \mathrm{da}$ & \\
\hline & $\mathrm{P}=26.45-2.77 \mathrm{w}-3.62 \mathrm{~d}$ & \\
V-notch & $+0.44 \mathrm{a}+4.11 \mathrm{w}^{2}+2.86 \mathrm{~d}^{2}$ & 0.9 \\
& $+3.16 \mathrm{a}^{2}-2.63 \mathrm{wd}$ & \\
& $-1.36 \mathrm{wa}+0.29 \mathrm{da}$ & \\
\hline
\end{tabular}

From the ANOVA and regression equations it can be concluded that depth and notch central angle are dominantly influencing the pressure bearing capacity under fatigue loading in rectangular notched specimens, while in the V-notched specimens, the depth and width are playing crucial role on the response undertaken. Higher coefficient of correlation obtained indicates a closer degree of relationship between the parameters and the response. The objective of the study is to estimate the pressure bearing capacity under fatigue loading. Higher the pressure required to be applied indicates higher fatigue strength of the specimen under notched conditions. The surface plots of the rectangular and V-notched specimens are illustrated in Figure 11 and Figure 12. In the rectangular notched cases, when width and angle are varying keeping the depth constant, the pressure is about $105 \mathrm{MPa}$ accruing to $75 \%$ of the pressure under un-notched condition. It is also found that the pressures are at the lowest ebbs when the depth and angle are governing the notch geometry at constant width. To the contrary, V-notched specimens have shown relatively higher pressure bearing capacities when the depth and angle are varying at a constant width. However, the maximum pressures they can withstand is inferior compared to the rectangular notched specimens and it accrues to around $50 \%$ of the pressure under un-notched condition.

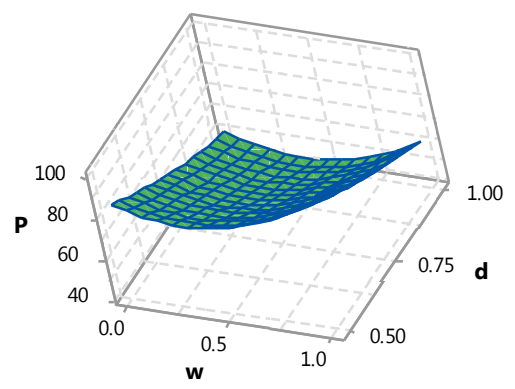

(i) Variation of Pressure with width and depth of notch

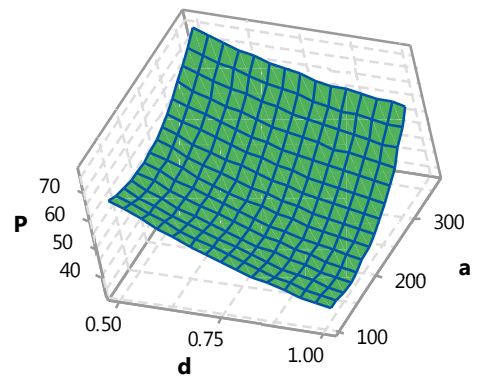

(iii) Variation of Pressure with depth and angle of notch

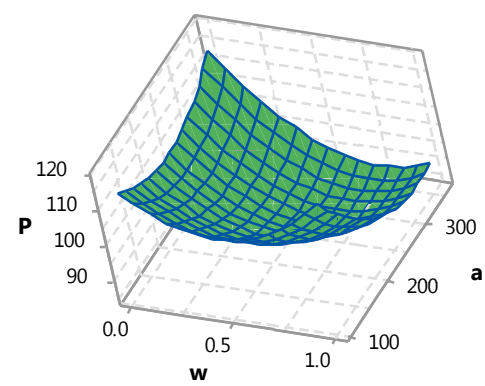

(ii) Variation of Pressure with width and angle of notch

Figure 11. Surface plots for rectangular notch 


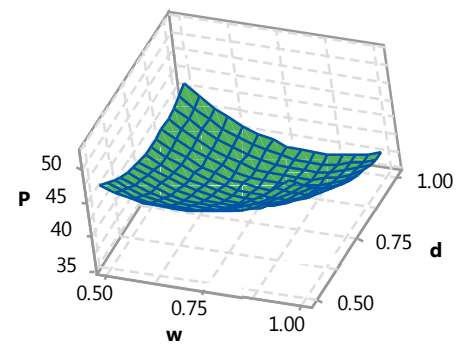

(i) Variation of Pressure with width and depth of notch

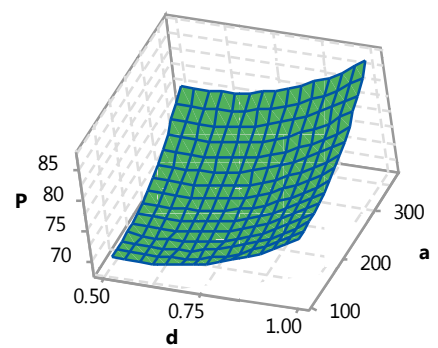

(iii) Variation of Pressure with depth and angle of notch

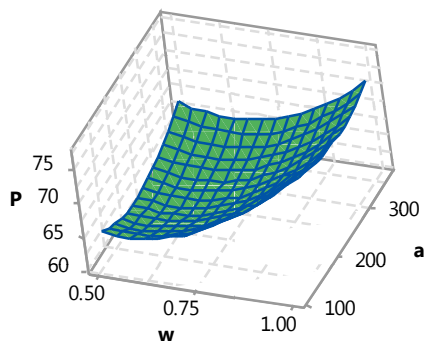

(ii) Variation of Pressure with width and angle of notch

Figure 12. Surface plots for V-notch

\section{Conclusions}

1. There is profound impact of notch geometry on the degradation of fatigue strength of any engineering structure.

2. Fatigue life is low with V-notched specimens compared to rectangular notched ones. This is concluded from the lower pressure bearing capacity of V-notched specimens when compared to their rectangular counterparts.

3. The V-notched specimens have $50 \%$ fatigue life while rectangular notched ones have $75 \%$ of fatigue life compared to un-notched specimen.

4. Higher coefficient of correlation yields a close relationship between parameters and the response.

\section{Abbreviations}

AISI: American Iron and Steel Institute

RSM: Response Surface Methodology

ASTM: American Society for Testing and Materials

FE: Finite Element

HCF: High Cycle Fatigue

ANOVA: Analysis of Variance

\section{Acknowledgements}

The authors express their deep sense of gratitude to the Chair, Department of Mechanical Engineering, Koneru
Lakshmaiah Education Foundation (Deemed to be University) and Director, Vidya Jyothi Institute of Technology for their continuous support during the execution of the current research.

\section{REFERENCES}

[1] Ralph I. Stephens, Ali Fatemi, Robert R. Stephens, Henry O. Fuchs, Metal Fatigue in Engineering, John Wiley \& Sons, 2001.

[2] M. Makkonen, Notch size effects in the fatigue limit of steel, International Journal of Fatigue, Vol. 25, Issue 1, pp. 17-26, 2002.

[3] G.H. Majzoobi and N. Daemi, The effects of notch geometry on fatigue life using notch sensitivity factor, Transactions of The Indian Institute of Metals, Vol. 63, Issues 2-3, pp. 547-552, April-June 2010.

[4] Y. T. Li, B. Chen, and C. F. Yan, "Effect of Parameters of Notch on Fatigue Life of Shaft Based on Product Lifecycle Management," Mater. Sci. Forum, vol. 638-642, pp. 3864 3869, 2010.

[5] M. T. Yu, D. L. DuQuesnay, T. H. Topper, International Journal of Fatigue, Vol. 10, Issue 2, pp. 109-116, 1988.

[6] G. Pluvinage, Fatigue and fracture emanating from notch; the use of the notch stress intensity factor, Nuclear Engineering and Design, Vol. 185, pp. 173-184, 1998.

[7] Xuteng Hu, Xu Jia, Zhenqiang Bao, Yingdong Song, Effect 
of notch geometry on the fatigue strength and critical distance of TC4 titanium alloy, Journal of Mechanical Science and Technology, Vol. 31, Issue 10, pp. 4727 - 4737, 2017.

[8] Yoshiaki Akiniwa, Nobuyuki Miyamoto, Hirotaka Tsuru, Keisuke Tanaka, Notch effect on fatigue strength reduction of bearing steel in the very high cycle regime, International Journal of Fatigue, Vol. 28, 1555-1565, 2006.

[9] G. Sreeram Reddy, V.V.Satyanarayana, M.Manzoor Hussian, J. Jagadesh Kumar, Response prediction of reverse engineered freeform surface by design of experiments, Journal of Mechanical Engineering and Sciences, Vol. 12, Issue 4, pp. 4231-4242, 2018.

[10] V.V. Satyanarayana, A. Chennakesava Reddy, and S. Sundararajan, Reduction of Casting Porosity in the Lost Wax Process Choosing Right Coating Materials by Response Surface Criteria, CEMILAC Conference, Ministry of Defence, India, 20-21 August, pp. 110-114, 1999.

[11] Douglas C. Montgomery, Design and Analysis of Experiments, 8th Edition International Student Version, Wiley Publishing Company, 2012. 